\title{
Editorial: Nano-Hetero-Structures for Chemical Sensing: Opportunities and Challenges
}

\author{
Sheikh A. Akbar ${ }^{1 *}$, Qasem A. Drmosh ${ }^{2}$ and Xiaogan $L i^{3}$ \\ ${ }^{1}$ The Ohio State University, Columbus, $\mathrm{OH}$, United States, ${ }^{2}$ King Fahd University of Petroleum and Minerals, Dhahran, \\ Saudi Arabia, ${ }^{3}$ Dalian University of Technology, Dalian, China
}

Keywords: gas sensors, hydrogen sensors, volatile gas sensors, nitrogen dioxide sensors, nano-hetero-structure

\author{
Editorial on the Research Topic
}

Nano-Hetero-Structures for Chemical Sensing: Opportunities and Challenges

Developing novel materials with desired microstructure and active surfaces can bring about significant advances in the field of gas sensors. Nanostructured materials such as metal oxides, graphene and its derivatives, and metal sulfides have been established to have great potentials for use in gas sensing due to their high specific surface area, abundant surface active sites, large surface-to-volume ratio, and availability of crystal facets with high surface reactivity. Lately, there is a clear and steady tendency to explore the opportunities available from $1 \mathrm{D}, 2 \mathrm{D}$, and $3 \mathrm{D}$ nanostructured materials for fabrication of high-performance gas sensors for a wide variety of applications. Chemical gas sensors based on nano-hetero-structures provide novel opportunities to

OPEN ACCESS

Edited by:

Vardan Galstyan,

University of Brescia, Italy

Reviewed by:

Yuliya Silina

Saarland University, Germany

Matteo Valt,

University of Ferrara, Italy

${ }^{*}$ Correspondence:

Sheikh A. Akbar

akbar.1@osu.edu

Specialty section:

This article was submitted to

Functional Ceramics,

a section of the journal

Frontiers in Materials

Received: 15 November 2019 Accepted: 03 December 2019 Published: 17 December 2019

Citation:

Akbar SA, Drmosh QA and Li X (2019) Editorial: Nano-Hetero-Structures for Chemical Sensing: Opportunities and Challenges. Front. Mater. 6:332. doi: 10.3389/fmats.2019.00332 design sensors with improved performance in different applications such as agriculture, safety and security, environmental monitoring, and in medical applications to predict, monitor, and diagnose a wide range of diseases. However, there are still many challenges in the field of chemi-resistive gas sensors such as relatively poor sensitivity and selectivity to the low concentration especially at low operating temperature limiting their commercial viability.

This Frontiers in Materials Research Topic aims to present recent advances in the development of nano-hetero-structure-based chemical gas sensors which integrate experimental and theoretical resources and cutting-edge expertise in the fields of thin films, chemistry, physics, materials science, nanotechnology, and biotechnology.

This Research Topic contains a collection of 21 contributions: 1 review article and 20 original articles. Note that the web-page number count is 22, because one article appears twice: one is referred to as "original article" and the other "correction article." The title of the review article is "Gas Sensing by Microwave Transduction: Review of Progress and Challenges" by Li et al. The original articles include "Improved Gas Selectivity Based on Carbon Modified $\mathrm{SnO}_{2}$ Nanowires" by Tonezzer et al., "Synthesis, Characterization and Ethanol Sensing Properties of Nanocrystalline $\alpha-\mathrm{MoO}_{3}$ " by Sau et al., "A Simple Flow Injection Sensing System for the Real-Time On-Line Determination of Chemical Oxygen Demand Based on 3D Au-NPs/TiO $\mathrm{O}_{2}$ Nanotube Arrays" by Si et al., "Detection of Semi-volatile Plasticizers as a Signature of Early Electrical Fire" by Han et al., "Flame Spray Synthesis of $\mathrm{VOPO}_{4}$ Polymorphs" by Jodhani et al., "Light-Activated Sub-ppm $\mathrm{NO}_{2}$ Detection by Hybrid $\mathrm{ZnO/QD} \mathrm{Nanomaterials} \mathrm{vs.} \mathrm{Charge} \mathrm{Localization}$ in Core-Shell QD" by Chizhov et al., "Metal Decoration and Magnetic Field Effect on the Electrical Breakdown Voltage for ZnO Nanorods Gas Ionization Sensor" by Liu et al., "Three-Dimensional $\mathrm{Fe}_{3} \mathrm{O}_{4} @$ Reduced Graphene Oxide Heterojunctions for High-Performance Room-Temperature $\mathrm{NO}_{2}$ Sensors" by Zou et al., "Improvement of $\mathrm{NO}_{2}$ Sensing Properties in Pd Functionalized Reduced Graphene Oxides by Electron-Beam Irradiation" by Choi et al., "Silver Nanoparticle-Decorated Tin Oxide Thin Films: Synthesis, Characterization, and Hydrogen Gas Sensing" 
by Mohamedkhair et al., " $U V$ Light Activated $\mathrm{SnO}_{2} / \mathrm{ZnO}$ Nanofibers for Gas Sensing at Room Temperature" by Li et al., "Heating Method Effect on SnO Micro-Disks as $\mathrm{NO}_{2}$ Gas Sensor" by Masteghin et al., "Highly Sensitive and Selective Ethanol Sensor Based on $\mathrm{ZnO}$ Nanorod on $\mathrm{SnO}_{2}$ Thin Film Fabricated by Spray Pyrolysis" by Tharsika et al., "Sol-gel Synthesis of $\mathrm{TiO}_{2}$ With p-Type Response to Hydrogen Gas at Elevated Temperature" by Xie et al., "Improving Hydrogen Sensing Performance of $\mathrm{TiO}_{2}$ Nanotube Arrays by $\mathrm{ZnO}$ Modification" by Yu et al., "Improvement in $\mathrm{NO}_{2}$ Sensing Properties of Semiconductor-Type Gas Sensors by Loading of Au Into Porous $\mathrm{In}_{2} \mathrm{O}_{3}$ Powders" by Ueda et al., "Effect of Zinc Oxide Modification by Indium Oxide on Microstructure, Adsorbed Surface Species, and Sensitivity to CO" by Marikutsa et al., "Kinetic Insight on Improved ChemiResistive Response of Hydrothermal Synthesized Pt Loaded $\mathrm{TiO}_{2}$ Nano-rods Toward Vapor Phase Isopropanol" by Das et al., "HighPerformance Non-enzymatic Glucose Sensors Based on CoNiCu Alloy Nanotubes Arrays Prepared by Electrodeposition" by Gong et al., and "Enhanced Acetone-Sensing Properties of PEI Thin Film by GO-NH $\mathrm{H}_{2}$ Functional Groups Modification at Room Temperature" by Zhao et al.

The review of $\mathrm{Li}$ et al. summarizes the recent progress of microwave gas sensors including the characteristic of the various nanostructured materials, and propagative structures (non-resonator and resonator). Original articles in this Research Topic can be classified according to the target gas into four groups: nitrogen dioxide gas sensors (5 articles), hydrogen gas sensors ( 3 articles), volatile gas sensors (ethanol, isopropanol, and acetone) (4 articles), and other gas sensors (8 articles).

Multiple types of chemical gas sensors to detect $\mathrm{NO}_{2}$ gas have been demonstrated in this special issue. The paper by Choi et al. reports the effect of electron-beam irradiation on the $\mathrm{NO}_{2}$ gas-sensing properties of Pd-functionalized rGO. The so-fabricated sensors are subjected to different irradiation doses $(0,100$, and $500 \mathrm{kGy})$ and their $\mathrm{NO}_{2}$ gas-sensing performance are measured and compared. Their results show that the response of the fabricated sample increases with increasing the irradiation doses which is attributed by the authors to the formation of high energy defects. Zou et al. report the fabrication of a core-shell 3D $\mathrm{Fe}_{3} \mathrm{O}_{4} @ \mathrm{rGO}$ p-n heterojunctions using self-assembly method for $\mathrm{NO}_{2}$ gas sensor. The contribution from Chizhov et al. demonstrates that the illumination of $\mathrm{ZnO} / \mathrm{CdSe}$, $\mathrm{ZnO} / \mathrm{CdS} @ \mathrm{CdSe}$, and $\mathrm{ZnO} / \mathrm{ZnSe} @ \mathrm{CdS}$ nanocomposites fabricated by the immobilization of nanocrystals colloidal quantum dots by a green light $\left(\lambda_{\max }=535 \mathrm{~nm}\right)$ changes the population of surface states, which strongly affects the response of the fabricated materials toward $\mathrm{NO}_{2}$. Masteghin et al. compare the response of $\mathrm{SnO}$ micro-disks toward $\mathrm{NO}_{2}$ using two different heating methods: (1) self-heating in which the heater circuit deposited on the back side of the interdigitated electrode, and (2) external heating such as a tube furnace. According to their results, the external heating method shows higher sensor response and lower recovery time, which is ascribed by the authors to the lack of a temperature gradient between the $\mathrm{SnO}$ micro-disks and the sensor chamber atmosphere. In the study of Ueda et al., porous $\mathrm{In}_{2} \mathrm{O}_{3}$ powders loaded with noble metals ( $\mathrm{Pd}$, $\mathrm{Au}$, or $\mathrm{Pt}$ ) fabricated using ultrasonic spray pyrolysis and their
$\mathrm{NO}_{2}$ sensing properties are examined. The $\mathrm{Au}$ nanoparticles loading on the $\mathrm{In}_{2} \mathrm{O}_{3}$ show higher response toward $\mathrm{NO}_{2}$ than that of $\mathrm{Pd}$ or Pt loaded $\mathrm{In}_{2} \mathrm{O}_{3}$.

Furthermore, there are four papers focused on $\mathrm{H}_{2}$ sensing applications. Mohamedkhair et al. report the formation of welldispersed Ag nanoparticles over the surface of $\mathrm{SnO}_{2}$ thin films via $\mathrm{DC}$ reactive sputtering and a subsequent heat treatment process for detecting low concentration of $\mathrm{H}_{2}$ at low operating temperature. The so-fabricated sensor shows butter response compared to that of pristine and heated $\mathrm{SnO}_{2}$ films. They propose that the depletion layer caused by $\mathrm{Ag}, \mathrm{Ag}_{2} \mathrm{O}$, and $\mathrm{SnO}_{2}$ played a vital role in the improvement of $\mathrm{H}_{2}$ sensing properties. In another paper, Xie et al. discuss $\mathrm{H}_{2}$ sensing properties of $\mathrm{Cr}$ doped $\mathrm{TiO}_{2}$ nanoparticles fabricated by sol-gel method and investigates the effect of doping concentration (1-10 at.\%) on the gas sensing performance. $\mathrm{Yu}$ et al. investigate the hydrogen gas sensing behavior based on $\mathrm{ZnO}$ decorated onto the surface of $\mathrm{TiO}_{2}$ nanotubes, where anodization and facile impregnation synthesis methods are employed to fabricate $\mathrm{TiO}_{2}$ nanotubes and $\mathrm{ZnO}$ decorated $\mathrm{TiO}_{2}$.

The contribution from Sau et al. reports the fabrication of $\alpha$ $\mathrm{MoO}_{3}$ nanoparticles fabricated via facile sol-gel technique and their gas sensing properties for breath diagnostics applications. Although, the sensor is highly sensitive toward ethanol, it is insensitive toward the main interfering agent of exhaling human breath. The paper by Tharsika et al. reports the preparation of mixed structure of $\mathrm{ZnO}$ nanorod on $\mathrm{SnO}_{2}$ thin film via spray pyrolysis followed by thermal annealing and their gas sensing properties toward ethanol. In the study of Ueda et al., flower like architecture consisting of innumerable numbers of $\mathrm{TiO}_{2}$ nanorods are fabricated hydrothermally and subsequently modified chemically with platinum nanoparticles. The isopropanol gas sensing properties of the fabricated materials are examined at different temperatures and concentrations of isopropanol. In another paper, Zhao et al. focuses on fabrication of PEI/GO-NH $\mathrm{N}_{2}$ composite film on quartz crystal microbalance using a spraying and drop coating method. Furthermore, the acetone-sensing performance is explored at room temperature. $\mathrm{PEI} / \mathrm{GO}-\mathrm{NH}_{2}$ composite film sensor shows an enhancement in acetone sensitivity compared with the pristine PEI film.

Tonezzer et al. demonstrate that carbon modified $\mathrm{SnO}_{2}$ nanowires fabricated by chemical vapor deposition can be used as a sensing material to detect different gases (carbon monoxide, ammonia, acetone, ethanol, toluene, and hydrogen). Furthermore, machine learning algorithms are employed in their work to distinguish various gases based on the obtained data. Si et al. propose a real-time on-line sensing system combining with $3 \mathrm{D} \mathrm{Au}$ nanoparticles/ $/ \mathrm{TiO}_{2}$ nanotube sensing electrode and photoelectrochemical reactor for the determination of chemical oxygen demand. The proposed sensing system displays a linear range from about 2 to more than $3,000 \mathrm{mg} / \mathrm{L}$ with low detection limit of $0.18 \mathrm{mg} / \mathrm{L}$. The paper by Han et al. reports the detection of semi-volatile Dioctyl phthalate and 2Ethylhexanol released from over-heated PVC cables for early warning of electrical fire using $\mathrm{SnO}_{2}$ nanofibers synthesized via electrospinning followed by calcination at $600^{\circ} \mathrm{C}$ for $3 \mathrm{~h}$. The contribution from Jodhani et al. introduces a novel method 
to fabricate different $\mathrm{VOPO}_{4}$ polymorphs using two different organic compounds as precursors via flame spray pyrolysis. The article by Liu et al. focuses on the fabrication of $\mathrm{ZnO}$ nanorod arrays with sharp tips via chemical vapor deposition and use them as the anode for gas ionization sensor. The authors also explore the effects of metal (Ni81Fe19, Mn, and $\mathrm{Au}$ ) decoration and magnetic field on the electrical breakdown voltage. The synthesis of $\mathrm{SnO}_{2} / \mathrm{ZnO}$ nanocomposites composed of $\mathrm{SnO}_{2}$ nanofiber and $\mathrm{ZnO}$ nanorods is reported by $\mathrm{Li}$ et al. The soprepared sensor shows a good response to various concentrations of formaldehyde gas and a good selectivity against many possible interferents such as methanol, ethanol, acetone, toluene, and benzene at room temperature under UV irradiation. Marikutsa et al. focus on nanostructured $\mathrm{ZnO}$ modified by $1-7$ at.\% of indium synthesized via coprecipitation and annealing at $450^{\circ} \mathrm{C}$ and their $\mathrm{CO}$ gas sensing properties are tested at temperatures ranging from room temperature to $450^{\circ} \mathrm{C}$. Finally, the article by Gong et al. reports the preparation of $\mathrm{CoNiCu}$ alloy nanotube arrays using a template-assisted electrodeposition method. The glucose sensing performance of $\mathrm{CoNiCu}$ alloy nanotube arrays exhibits wider linear range, higher sensitivity, high selectivity to glucose, and low operation potential compared to that of single or binary alloy electrodes reported in literature.

While rapid progress in new synthesis routes has made it possible to engineer and optimize specific types of nano-heterostructures for a given application, the largely trial-and-error approach has failed to effectively understand and model the response behavior of these nano-hetero-structures in a way that could otherwise advance the field toward bottom-up design for specific applications. It is hoped that this Research Topic on nanostructured chemical gas sensors will be of great interest to the Frontiers in Materials readers and will inspire considerable future $R \& D$ activities and progress in the field.

The Editors are grateful to the authors and the reviewers for their contributions and cooperation in adhering to the timetable. Special thanks go to the Frontiers staff and editorial team for their outstanding support and collaboration during the entire process.

\section{AUTHOR CONTRIBUTIONS}

These authors were co-editors of the Research Topic and contributed equally to reviewing process. Each author contributed in the writing and editing of this editorial as well.

\section{FUNDING}

SA's time on this article was partly funded by the National Science Foundation grant 160914.

Conflict of Interest: The authors declare that the research was conducted in the absence of any commercial or financial relationships that could be construed as a potential conflict of interest.

Copyright $\odot 2019$ Akbar, Drmosh and Li. This is an open-access article distributed under the terms of the Creative Commons Attribution License (CC BY). The use, distribution or reproduction in other forums is permitted, provided the original author(s) and the copyright owner(s) are credited and that the original publication in this journal is cited, in accordance with accepted academic practice. No use, distribution or reproduction is permitted which does not comply with these terms. 